\title{
Determination of Pesticides in Aqueous Samples by Solid-Phase Microextraction In-Line Coupled to Gas Chromatography-Mass Spectrometry
}

\author{
Ralf Eisert and Karsten Levsen \\ Department of Analytical Chemistry, Fraunhofer Institute of Toxicology and Aerosol Research, Nikolai-Fuchs- \\ Strasse 1, D-30625 Hannover, Germany
}

\begin{abstract}
A multiresidue method was developed for the determination of nitrogen- and phosphorouscontaining pesticides (amines, anilides, phosphorothioates, and triazines) by solid-phase microextraction (SPME) in-line coupled to gas chromatography-mass spectrometry (GC/MS). The $85-\mu \mathrm{m}$ polyacrylate fiber was first dipped into the aqueous sample for a given time and then directly introduced into the heated injector of the gas chromatography-mass spectrometer, where the analytes are thermally desorbed. The method was evaluated with respect to the limit of detection, linearity, and precision. The limit of detection [selected ion monitoring (SIM) mode] depends on the compound and varies from 5 to $90 \mathrm{ng} / \mathrm{L}$. The method is linear over at least 3 orders of magnitude with coefficients of correlation usually $\geq 0.996$. In general, the coefficient of variation (precision) is $<10 \%$. The partitioning of the analyte between the aqueous phase and the polymeric phase depends on the hydrophobicity of the compound as expressed by the octanol-water partitioning coefficient $P_{\text {ou... }}$. The addition of sodium chloride has a strong effect on the extraction efficiency. This effect increases with decreasing hydrophobicity (increasing polarity) of the compound.

The triazines atrazine, simazine, and terbuthylazine were first identified and quantified in water samples from the effluent of sewage plants by SPME-gas chromatographynitrogen-phosphorus detection (GC/NPD). For such a complex matrix GC/NPD is not sufficiently selective for an unambiguous identification at low levels $(<1 \mathrm{ppb})$ of pesticides. Selectivity may be enhanced by using SMPE-GC/MS in the SIM mode with three characteristic ions for each pesticide. This method allows an unequivocal identification and quantification at low levels of pesticides in environmental samples.

At a target limit of detection below $100 \mathrm{ng} / \mathrm{L}$, SPME-GC/MS represents a very simple, fast, selective, and solvent-free multimethod for the extraction and determination of these nitrogen- and phosphorous-containing pesticides from aqueous samples. (f Am Soc Mass Spectrom 1995, 6, 1119-1130)
\end{abstract}

I n general, most organic pollutants in aqueous environmental samples, that is, pesticides, have to be extracted and enriched before their instrumental determination. In the past, sample preparation was dominated by conventional liquid-liquid extraction, a time-consuming method for which large amounts of solvents are necessary. This technique has been largely replaced in the past few years by solid-phase extraction (SPE) which uses a variety of sorbents [1-5]. This method is less time-consuming because many samples can be enriched in parallel and less (toxic) solvents are needed. Furthermore, automation of the extraction process is possible. Recently, a new extraction technique, solid-phase microextraction (SPME), was intro-

Address reprint requests to Prof. Dr. Karsten Levsen, Department of Analytical Chemistry, Fraunhofer lnstitute of Toxicology and Acrosol Research, Nikolai-Fuchs-Strasse 1, D-30625 Hannover, Germany. duced by Pawliszyn and co-workers [6-8]. This method represents a further important advance in the efficient extraction of organic pollutants from aqueous samples at trace levels. The theory of the extraction process and some first applications were published by Pawliszyn et al. $[7,9]$. The authors applied this technique predominantly to the extraction and determination of volatile organic compounds, such as benzene, toluene, and xylenes (BTX), and chlorinated hydrocarbons by using a polymeric fiber with polydimethylsiloxane [8-11], but also to less volatile aromatic compounds such as polycyclic hydrocarbons (PAHs) $[12,13]$, phenols, and nitrophenols by using for example, a polyacrylate phase $[14,15]$. Moreover, a modification of this method for headspace analysis has been reported $[12,16]$. Quantitative extraction in headspace analysis was recently achieved by using an internally cooled SPME device for the determination of BTX [16]. 
The SPME method shows several attractive features: It is very simple to handle, fast, easy to automate by use of a commercially available autosampler $[8,17]$, and-what seems to be a completely new physical aspect for the extraction process-it works without any solvent.

With this method, which is described in more detail in the Experimental section, a fused silica fiber coated with an immobilized liquid phase (i.e., polydimethylsiloxane or polyacrylate) as a stationary phase, is used for the extraction of organic trace compounds from water samples simply by dipping the fiber into the aqueous sample [11-28]. Hence sampling, extraction, and concentration are focused in a single step. After absorption equilibrium is achieved (or after a defined time), the fiber is transferred into the hot injector of the gas chromatograph and exposed for a given period of time, where the organic compounds are thermally desorbed from the stationary phase. This desorption is quantitative, that is, no memory effects are observed. The total amount of extracted sample is used for the determination by gas chromatography (in contrast to conventional extraction methods).

The fiber can be used repeatedly for extraction. Moreover, the method does not make use of any solvents. Finally, very small sample volumes, $3-5 \mathrm{~mL}$, are sufficient for the analysis. The dynamics of this extraction process and the transfer of the analytes into the polymeric microphase is a diffusion-determined process [9]. Until equilibrium is achieved, the concentration near the fiber and thus the diffusion of the analyte decreases. Therefore, the transport of the analytes to the fiber can be enhanced by stirring the aqueous sample.

\section{Theory}

The partitioning of analytes between the aqueous sample and the immobilized liquid film on the fiber is the main principle on which SPME is based. The amount of analyte absorbed by the polymeric microphase on the fiber at equilibrium (infinite volume assumed) is proportional to the concentration in the aqueous solution and is determined by the partitioning constant according to

$$
n=\frac{K_{\mathrm{fs}} V_{\mathrm{f}} C_{\mathrm{u}} V_{\mathrm{s}}}{K_{\mathrm{fs}} V_{\mathrm{f}}+V_{\mathrm{s}}}
$$

where $n$ is the number of moles of the analyte absorbed by the stationary phase, $K_{f s}$ is the partitioning coefficient of an analyte between the stationary and the aqueous phase, $V_{\mathrm{f}}$ and $V_{\mathrm{s}}$ are the volumes of the stationary phase and the sample, and $C_{0}$ is the initial concentration of the analyte in the aqueous phase.

Louch et al. [9] showed that for the case of $V_{s} \gg$ $K_{\mathrm{fs}} V_{\mathrm{f}}$ the amount of analyte extracted by the polymeric film is given by

$$
n=K_{\mathrm{fs}} V_{\mathrm{f}} \mathrm{C}_{0}
$$

and is not related to the sample volume. Thus, there is a linear relationship between the concentration of the analytes in the aqueous samples and the amount absorbed on the fiber and hence the response of the gas chromatography (GC) detector if the absorption conditions in the sample and the desorption conditions in the injection port of the gas chromatograph are reproducible. A mathematical model for the dynamics of the absorption process was developed by Louch et al. [9] under the assumption that the dynamics of extraction and thus the extraction times are diffusion-controlled processes. Based on Fick's second law, they calculated time profiles for perfectly stirred and unstirred samples of infinite volume. They demonstrated that the time to reach the equilibrium concentrations in a perfectly agitated sample is relatively short. Without intensive mixing of the aqueous solution, the equilibration time increases considerably. In this static case, transport of the analyte is limited by the diffusion in both the aqueous phase and the aqueous layer at the fiber surface. During the absorption process, the concentration gradient at this layer steadily decreases and thus reduces the flux into the fiber. In the dynamic case (extensive stirring) a layer of water still remains on the surface of the polymeric fiber so that the final equilibration time is determined by diffusion through this layer.

In this study, the SPME method was applied to the extraction of pesticides from aqueous samples. Pesticides are used extensively in agriculture throughout the world to protect plants against pests, fungi, and weeds. If these pesticides are not biodegraded within the soil, they may leach down to the ground water table, which may lead to extensive pollution of ground water [29]. This pollution represents a possible risk for drinking water production because in many countries ground water is the main source for drinking water production and supply. The purpose of this work is to evaluate the applicability of SPME-gas chromatography-mass spectrometry (GC/MS) as a fast and simple method for the extraction and quantification of pesticides with a target limit of detection of $50 \mathrm{ng} / \mathrm{L}$, which is necessary to verify the maximum permissible level of $100 \mathrm{ng} / \mathrm{L}$ that is set by the European Union in its drinking water regulations [30]. A SPME-gas chromatography-atomic emission detection (GC/AED) and SPME-gas chromatography-nitrogen-phosphorus detection (GC/NPD) method for the determination of a few pesticides with different SPME fibers has been described by us previously [31, 32]. In this study, a $85-\mu \mathrm{m}$ polyacrylate fiber was used for extraction of organophosphorus pesticides, triazines and other $\mathrm{N}$ heterocyclic compounds, that is, anilides and N-substituted amines. Parameters that may affect the extraction, like the addition of sodium chloride, different concentrations of humic acid, and competition be- 
tween major and minor components during the SPME process, have been investigated. Although we previously used a GC/NPD to identify and quantify low levels of these pesticides, a GC/MS system was preferred in this study to monitor target pesticides in environmental samples and thus enhance the selectivity of the method. GC/MS can be used either to verify tentative identification by GC or for direct determination. Further automation of this method to develop an on-site analysis system is in progress. This on-site system will allow surveillance of surface water for organic pollutants by quasicontinuous monitoring.

\section{Experimental}

\section{Materials}

All pesticide standards used in this study were purchased from Promochem (Wesel, Germany) and Riedel-de-Haën (Seelze-Hannover, Germany). They were mostly of purity $>97 \%$ and used as received. Methanol (PESTANAL quality) and heptadecanoic acid nitrile $(98 \%)$ were also from Riedel-de-Haën. Water was obtained from a Milli-Q water purification system (Millipore/Extrel, Pittsburgh, PA). Sodium chloride (R.G.) of quality $>99.5 \%$, a humic acid standard, and heptacosafluorotributhylamine (calibration standard for MS experiments, reference masses) was purchased from Fluka (Buchs, Switzerland).

\section{Experimental Equipment}

The gas cliromatograph-mass spectroneter. GC/MS investigations were carried out using a Hewlett-Packard (Avondale, PA) type 5890 gas chromatograph coupled to a 70-SQ mass spectrometer from Fisons Analytical Instruments Limited (Manchester, England) operated under electron impact (EI) conditions. The mass spectrometer was scanned either over the range $m / z$ 40-500 or time-scheduled selected ion monitoring (SIM) was performed. The screening for all pesticides was carried out by monitoring all molecular ion masses (see Table 2, where quantitation ions are in bold letters). For confirmation of pesticides tentatively identified by SIM, such as triazines, two typical fragment ions (see Table 2) were monitored in addition to the molecular ion.

The gas chromatograph was equipped with a PTE-5 column ( $30 \mathrm{~m}, 0.32-\mathrm{mm}$ i.d., $0.25 \mu \mathrm{m} \mathrm{d}$ ) from Supelco (Bellefonte, PA), and a split-splitless injector with a deactivated insert (2-mm i.d.) of $250-\mu \mathrm{L}$ volume. The following temperature program was used: $60^{\circ} \mathrm{C}$ for 2 $\min , 60-180^{\circ} \mathrm{C}$ at $30^{\circ} \mathrm{C} / \mathrm{min}, 180^{\circ} \mathrm{C}$ for $2 \mathrm{~min}$, $180-200^{\circ} \mathrm{C}$ at $2{ }^{\circ} \mathrm{C} / \mathrm{min}, 200^{\circ} \mathrm{C}$ for $1 \mathrm{~min}, 200-280^{\circ} \mathrm{C}$ at $8^{\circ} \mathrm{C} / \mathrm{min}, 280^{\circ} \mathrm{C}$ for $1 \mathrm{~min}$ (total run time $30 \mathrm{~min}$ ). All injections with the SPME unit were performed manually (for injector temperature, see Solid Phase Microextraction Procedure, which follows). The liner purge was closed during the desorption of the analytes from the SPME fiber in the split-splitless injector (2-min delay). For comparative GC determinations, a Hewlett-Packard type 5890 series II gas chromatograph equipped with a nitrogen-phosphorus detector (NPD) and a split-splitless injector was employed.

Solid-phase microextraction. A solid-phase microextraction (SPME) fiber holder for manual use with a $85-\mu \mathrm{m}$ polyacrylate fiber from Supelco was used for all SPME experiments.

\section{Solid-Phase Microextraction Procedure}

Standard conditions. The procedure for SPME is very simple because there is no further sample preparation step. First, the fiber is exposed to the sample for a period described below. Second, the fiber is withdrawn from the sample and introduced directly into the gas chromatograph injector, where thermal desorption occurs.

Fiber with an $85-\mu \mathrm{m}$ polyacrylate phase was employed for all three investigated pesticide classes (organophosphorus, triazine, and aniline compounds). An optimized absorption time $(30 \mathrm{~min})$ was used in this study, when no other parameters are mentioned. This time does not necessarily represent the equilibration time. Thermal desorption of the pesticides in the hot gas chromatograph injector (vide infra) was carried out for $2 \mathrm{~min}$. After this period, the liner purge of the gas chromatograph injector was closed and the liner was purged by the GC carrier flow. After desorption, the fiber was still kept in the liner for an additional 3 min to remove possible memory effects, especially if environmental samples were investigated. After this period no significant blank values were observed (see Figure 2). No further regeneration mode for the fiber assembly was necessary.

The injector temperature of the gas chromatograph was kept at $250^{\circ} \mathrm{C}$ for desorption of the pesticides. The peaks of all compounds show only very little or no tailing. For the investigated compounds there is no need for further trapping of the analytes during or after the desorption step.

Five milliliters of the aqueous sample were filled into $10-\mathrm{mL}$ headspace vials. Optimum mixing of the liquid phase was achieved by magnetic stirring. Therefore a $6 \times 3-\mathrm{mm}$ magnetic stirring bar was added before exposure of the fiber. Concentration versus exposure time profiles were determined by using water from a Milli-Q purification system spiked with a standard solution (sample concentration $24 \mathrm{ng} / \mathrm{mL}$ of each pesticide). Adsorption at the stationary phase of air bubbles, which have a significant effect on precision, should be avoided and can be removed by sonification.

Experiments with salt addition. Experiments were carried out with concentrations of sodium chloride varying from 0 to $100 \%$ (saturated solution). The sodium chloride standard was prepared in Milli-Q water. 
Experiments with humic acids. The effect of humic acid addition on the extraction of triazine pesticides was studied in Milli-Q water samples spiked with a humic acid standard. The concentration of humic acids was varied from 0.1 to $100 \mathrm{mg} / \mathrm{L}$ [typical dissolved organic carbon (DOC) values measured in surface water samples].

Concentration effects during the SPME process. Experiments during the SPME process were carried out to investigate the influence of high concentrations of organic compounds with a high affinity to the SPME phase on the absorption of minor components. To this end the concentration of terbuthylazine was varied from 18 to $12000 \mathrm{ng} / \mathrm{mL}$ in the aqueous solution, while the concentration of the other triazine pesticides were kept constant at $18 \mathrm{ng} / \mathrm{mL}$ during these experiments. All extractions were carried out with saturated sodium chloride solutions. The standards were prepared in methanol. Spiking of the sample was done in such a way that the final content of methanol was kept to a minimum and kept constant.

Environmental samples. Water samples from several wastepipes of sewage plants (near Darmstadt, Germany) were extracted by SPME under standard conditions by using sodium chloride saturated solutions. Suspended particles of the samples were filtered off using silanized glass wool.

\section{Results and Discussion}

\section{The Absorption Process}

Table 1 lists the pesticides investigated in this study. During solid-phase microextraction an equilibrium of the analyte between the aqueous and the polymer phase is established. The partitioning coefficient, which is not determined here, is compound dependent and thus may vary substantially even within one compound class, as shown below.

Figure 1 describes the time dependence for the equilibration of the analytes between the aqueous and the polymeric phase for the anilide propachlor with the $85-\mu \mathrm{m}$ polyacrylate fiber. It is apparent from this figure that, for anilides, concentration equilibria are almost achieved within $2 \mathrm{~h}$ under intensive stirring of the solution. Organophosphorus compounds and triazines show a similar behavior for this fiber. For routine analysis, it is not necessary to reach a complete equilibrium as long as the exposure time of the fiber is kept exactly constant, as mentioned in the Introduction. An exposure time of $30 \mathrm{~min}$ is a reasonable compromise for a good peak response at an acceptable time. Moreover, this is also a typical time for the chromatography. Thus, during the GC run the subsequent sample is extracted.

By using an optimized injection time there could be no significant memory effect observed even after a
Table 1. Pesticides investigated in this study

\begin{tabular}{|c|c|}
\hline $\begin{array}{l}\text { Anilides and N-Substituted } \\
\text { Amines }\end{array}$ & $\begin{array}{l}\text { Triazines and N-Heterocyclic } \\
\text { Compounds }\end{array}$ \\
\hline Alachlor & Ametryn \\
\hline Benfluralin & Atraton \\
\hline Butralin & Atrazine \\
\hline Dimethachlor & Desmetryn \\
\hline Dinitramine & Metribuzin \\
\hline Ethalfluralin & Prometon \\
\hline Fenfuram & Prometryn \\
\hline Fluchloralin & Propazine \\
\hline Isopropalin & Sebuthylazine \\
\hline Mepronil & Secbumeton \\
\hline Metalaxyl & Simazine \\
\hline Metazachlor & Simetryn \\
\hline Metolachlor & Terbumeton \\
\hline Pendimethalin & Terbuthylazine \\
\hline Pretilachlor & Terbutryn \\
\hline \multicolumn{2}{|l|}{ Profluralin } \\
\hline \multicolumn{2}{|l|}{ Propachlor } \\
\hline \multicolumn{2}{|c|}{ Organophosphorus compounds } \\
\hline Azinphos-ethyl & Ethoprophos \\
\hline Bromophos-ethyl & Etrimphos \\
\hline Bromophos-methyl & Jodfenphos \\
\hline Chlorfenvinphos & Parathion-ethyl \\
\hline Chlorpyriphos-ethyl & Parathion-methyl \\
\hline Chlorpyriphos-methyl & Pirimiphos-methyl \\
\hline Chlorthion & Prothiophos \\
\hline Cyanophos & Sulfotep \\
\hline Diazinon & \\
\hline
\end{tabular}

spiked aqueous sample run, which was demonstarted in Figure 2 (the still existing peak results from an unknown compound of the drinking water sample that was used for spiking experiments). Figure 3 summarizes the GC/MS chromatograms (total ion current) of all investigated pesticides. In principle, all analytes could be analyzed in a single chromatogram. As several agents coelute, the compounds were grouped according to the four compound classes in Figure 3.

Furthermore, Figure 1 shows the effect of mixing the aqueous solution during the extraction step. The curve in the exposure-time profile with mixing is steeper and in general reaches the equilibrium five times earlier than without mixing. From similar exposure-time profiles of all other investigated pesticides, it is apparent that the extraction efficiency (which depends on the absorption equilibria) differs substantially for the various compounds, which is particularly the case with triazines.

Thus, for triazine pesticides, there is a pronounced decrease in the relative peak response after SPME if compared to the standard chromatogram, even for chemically related compounds, that is, simazine < atrazine $<$ propazine $<$ terbuthylazine. This may be explained by differences in the hydrophobicity, as ex- 


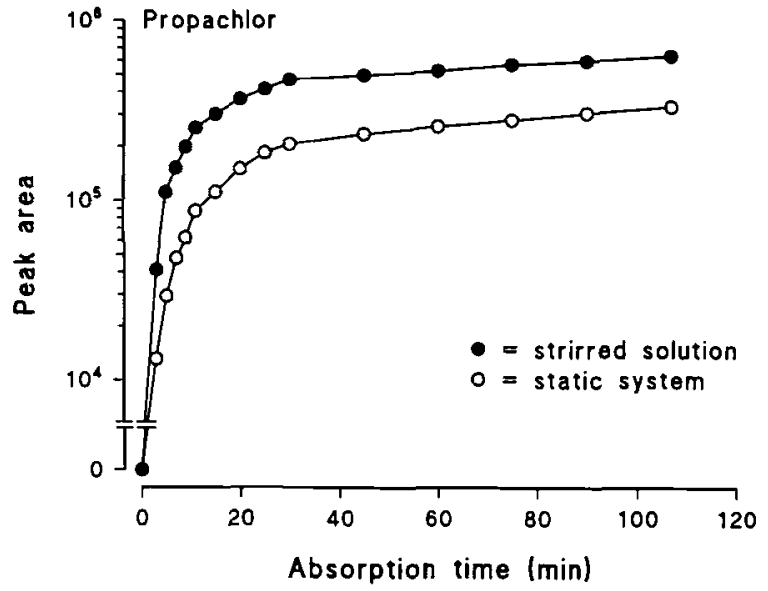

Figure 1. Time dependence for equilibration of propachlor between the aqueous and the polyacrylate phase. The extraction was performed from a sodium chloride saturated aqueous solution spiked with propachlor at $24 \mathrm{ng} / \mathrm{mL}$. Two exposure time profiles are shown-one with intensive stirring of the aqueous sample and the other without mixing.

pressed by the octanol-water partitioning coefficient $P_{\text {ow }}$ [33], which decreases from terbuthylazine to simazine (see Figure 4). A similar observation is made for another group of chemically related triazines, that is, simetryn, ametryn, prometryn, and terbutryn where, again, a decrease of relative peak response is observed from terbutryn to simetryn after extraction, which correlates with a decrease in $P_{\text {ow }}$. A linear relationship of the peak response as a function of the $P_{\mathrm{ow}}$ is obtained (see Figure 4).

It is apparent that the equilibration of the analyte between the aqueous and the polymeric phase depends on the hydrophobicity of the compound. The more hydrophobic (less polar) compounds are absorbed more readily by the polymeric phase. This strong dependence of the peak response on the polarity (hydrophobicity) of the analyte appears to be a disadvantage of the method presented here. However, as shown in the following section, this apparent disadvantage may be overcome by using the salt effect, which leads to low limits of detection, a good linearity, and precision for all investigated compounds.

\section{Method Validation}

For some of the investigated pesticides the method validation was performed using an GC/NPD as published previously by us [32]. Furthermore, the use of different SPME fibers for extraction of organophosphorus pesticides was described. Here data obtained with GC/MS are reported (see Table 2).

Linearity. The linearity of the calibration curve has been studied for all pesticides via SPME over a concentration range of $0.06-60 \mathrm{ng} / \mathrm{mL}$. The linearity is good ( $r \geq 0.996$ for most compounds), which allows the quantification of these agents by the method of exter- a

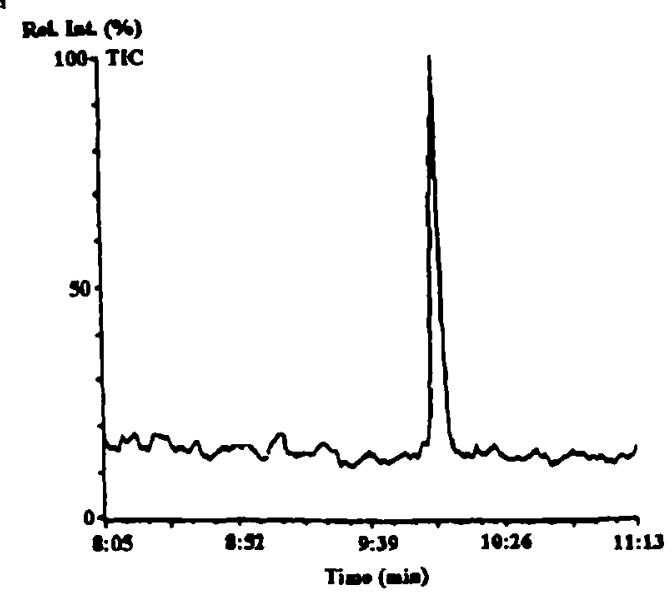

b

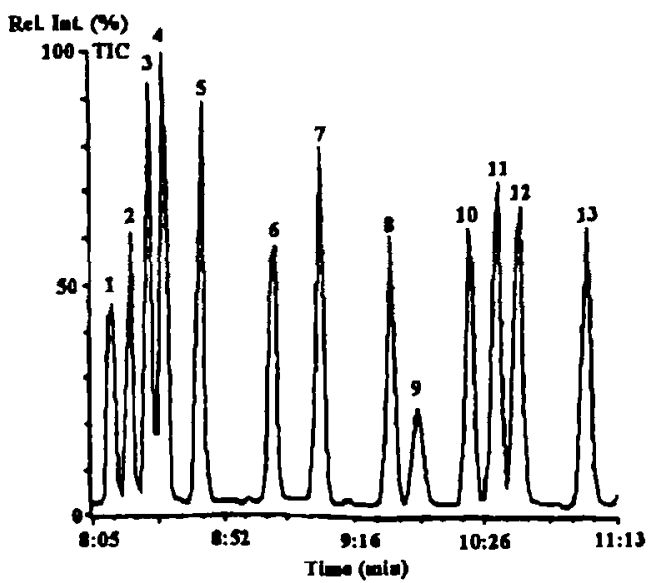

c

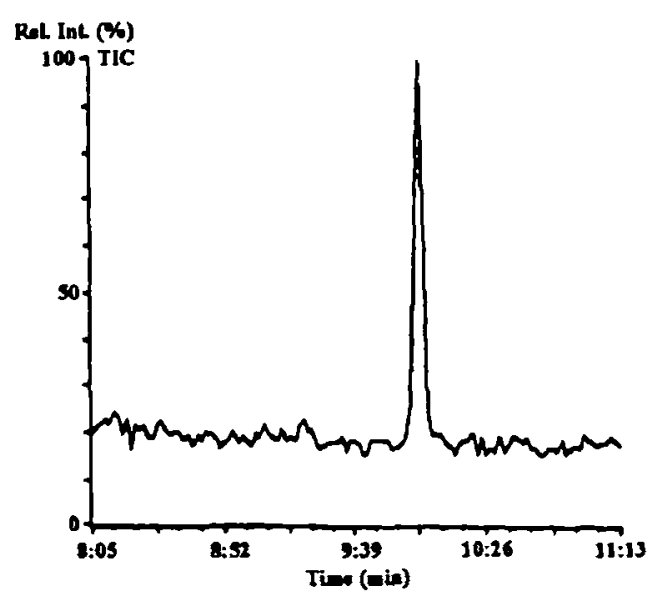

Figure 2. Illustration of fiber conditions before and after an extraction with 13 triazines at a concentration of $24 \mathrm{ng} / \mathrm{mL}$. (a) The significant time interval for the triazine, where only one spike from drinking water (unknown species) is present. (b) The GC run of the triazine SPME enrichment. For peak assignment, see Table 3. (c) The blank of the fiber directly after run (b); no significant memory effect of the triazines was observed under these developed standard conditions. 


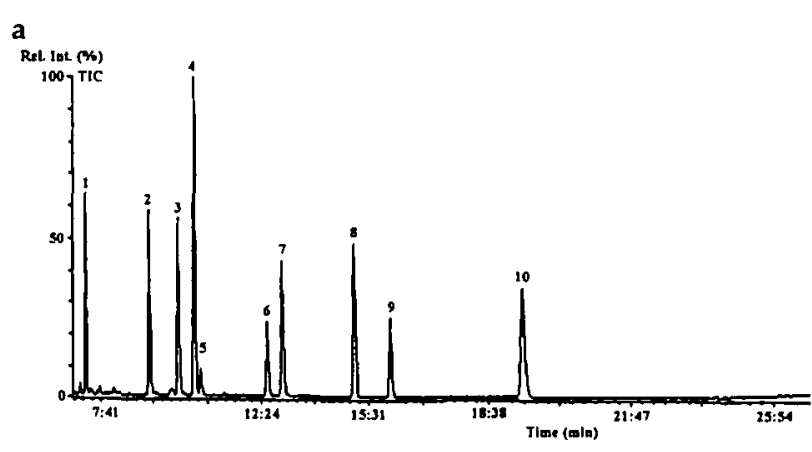

b

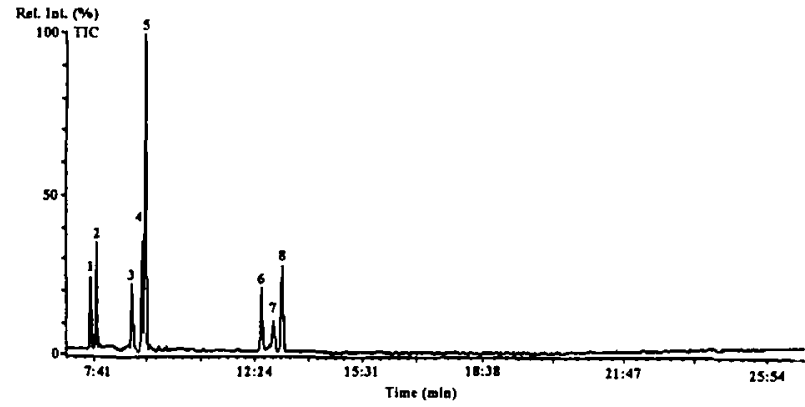

C

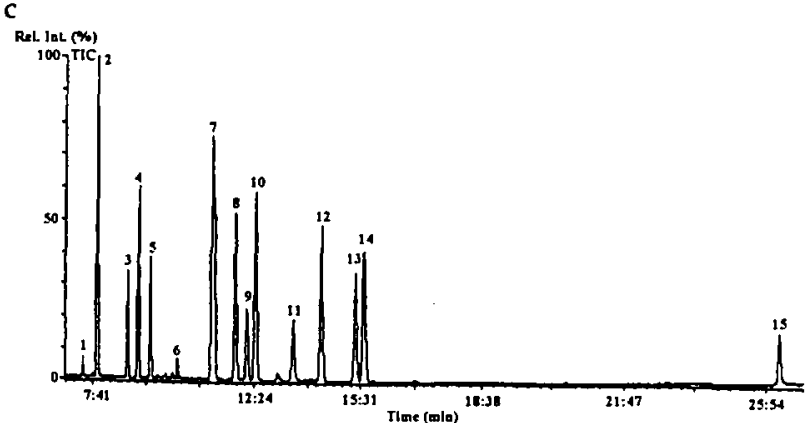

d

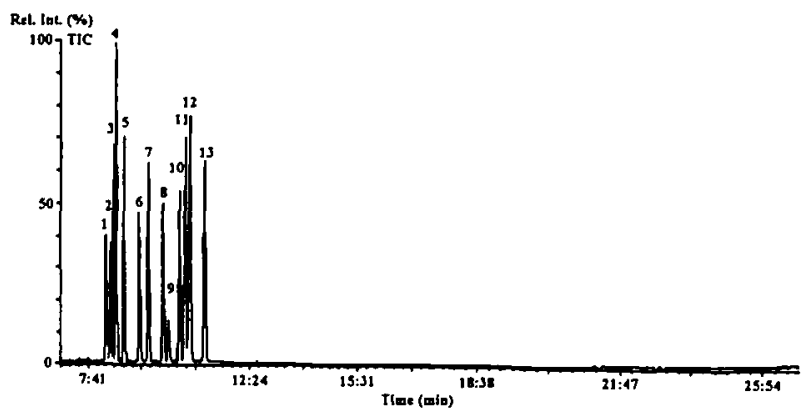

Figure 3. Gas chromatogram of 10 anilides (a), eight 2,6-dinitroanilines (b), 15 organophosphorus pesticides (c), and 13 triazines (d) after extraction of 5-mL water sample spiked with 60 $\mathrm{ng} / \mathrm{mL}$ by the SPME fiber. For peak assignment, see Table 3.

nal standardization. Calibration performed in this way includes both the extraction and instrumental determination. If matrix effects especially in environmental samples are not reproducible, the use of internal standards (i.e., heptadecanoic acid nitrile which is amenable to NPD and MS detection) should be included. Optimum quantification may be achieved if isotopical la-

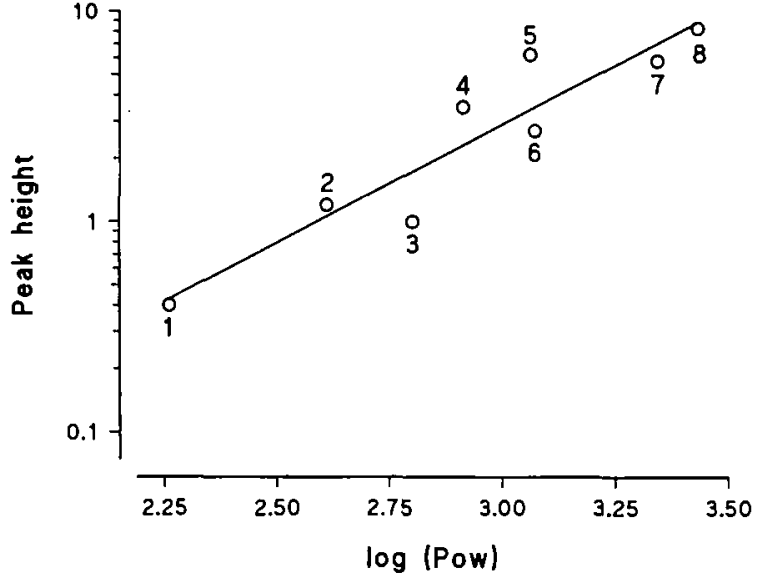

Figure 4. Response (extraction efficiency) of some triazine pesticides versus the octanol-water partitioning coefficient $P_{\mathrm{uw}}$ (double logarithmic scale). Assignment: 1 = simazine; 2 = atrazine; $3=$ simetryn; $4=$ propazine; $5=$ terbuthylazine; $6=$ ametryn; $7=$ prometryn; $8=$ terbutryn.

beled standards of target compounds that show a very similar chemical and physical behavior as the target compounds themselves are available.

Limits of detection. Table 3 shows the limits of detection (LOD) under SIM conditions. As a result of different peak responses apparent from Figure 3 and Table 3, the LOD differs substantially for the various compounds. These differences are even more pronounced for organophosphorus compounds as compared to triazines and anilides. For most compounds, the LODs are below $50 \mathrm{ng} / \mathrm{L}$ (SIM mode). These very low detection limits are remarkable considering the small sample volume ( $5 \mathrm{~mL}$ ). The permissible level for pesticide contamination set in the European Drinking Water Regulation (100 ng/L) [30] can be verified without difficulty by this method. The LOD of most pesticides was obtained by monitoring their molecular ion masses, although these molecular ions often do not represent the most abundant ions (see Table 2 ).

Precision. The precision of the method determined by extraction in triplicate was studied over at least 3 orders of magnitude. For most of the investigated pesticides the coefficient of variation $(\mathrm{CV})$ ranges from 3 to $10 \%$ with the $85-\mu \mathrm{m}$ polyacrylate phase. However, for the late eluting organophosphorus compounds these CVs can reach values up to $15 \%$. An improvement of this precision is conceivable. If SPME of organophosphorus compounds is carried out with a fiber coated with polydimethylsiloxane, a substantially better precision is achieved, which was demonstrated in a former publication [32]. The precision for triazines and anilides is considerably better ( $C V<8 \%$ ).

The extraction of all three compound classes was carried out under identical conditions (30-min absorption time with intensive stirring). Although at this time equilibrium concentrations were not yet achieved for 
Table 2. Elution order and main ions used for identification in the SPME-GC/MS analysis of important pesticides

\begin{tabular}{|c|c|c|c|c|}
\hline \multicolumn{2}{|c|}{ Compound } & \multirow[b]{2}{*}{$\alpha_{i}$} & \multirow[b]{2}{*}{$M_{\mathrm{n}}^{\mathrm{b}}$} & \multirow{2}{*}{$\begin{array}{c}\text { Main ions (used for identification } \\
\text { and quantitation) } \\
m / z \text { (relative abundance) }^{c}\end{array}$} \\
\hline No. & Common name & & & \\
\hline 1 & Propachlor & 0.594 & 211 & $211(26), 176(68), 120(100)$ \\
\hline 2 & Ethoprophos & 0.602 & 242 & $242(55), 200(45), 158(100)$ \\
\hline 3 & Ethalfluralin & 0.610 & 333 & $333(16), 316(52), 292(32)$ \\
\hline 4 & Benfluralin & 0.619 & 335 & $335(8), 318(8), 295(100)$ \\
\hline 5 & Sulfotep & 0.622 & 322 & $322(100), 294(48), 266(74)$ \\
\hline 6 & Atraton & 0.676 & 211 & $211(45), 196(100), 169(45)$ \\
\hline 7 & Simazine & 0.679 & 201 & $201(100), 186(60), 173(43)$ \\
\hline 8 & Prometon & 0.682 & 225 & $225(85), 210(100), 183(40)$ \\
\hline 9 & Atrazine & 0.684 & 215 & $215(72), 200(100), 173(24)$ \\
\hline 10 & Propazine & 0.688 & 229 & $229(68), 214(100), 187(29)$ \\
\hline 11 & Terbumeton & 0.692 & 225 & $225(34), 210(100), 169(70)$ \\
\hline 12 & Terbuthylazine & 0.699 & 229 & $229(37), 214(100), 173(33)$ \\
\hline 13 & Cyanophos & 0.701 & 243 & $243(100), 180(7), 125(43)$ \\
\hline 14 & Profluralin & 0.704 & 347 & $347(6), 330(13), 318(31)$ \\
\hline 15 & Diazinon & 0.748 & 304 & $304(84), 276(35), 199(62)$ \\
\hline 16 & Fluchloralin & 0.752 & 355 & $355(7), 326(80), 306(100)$ \\
\hline 17 & Fenfuram & 0.755 & 201 & $201(45), 202(7), 109(100)$ \\
\hline 18 & Secbumeton & 0.755 & 225 & $225(25), 210(24), 196(100)$ \\
\hline 19 & Dinitramine & 0.756 & 322 & $322(8), 305(100), 261(23)$ \\
\hline 20 & Etrimphos & 0.768 & 292 & 292 (100), 277 (50), 181 (98) \\
\hline 21 & Sebuthylazine & 0.769 & 229 & $229(17), 214(15), 200(100)$ \\
\hline 22 & Desmetryn & 0.790 & 213 & $213(100), 198(64), 171(30)$ \\
\hline 23 & Dimethachlor & 0.830 & 255 & $255(4), 210(19), 197(50)$ \\
\hline 24 & Metribuzin & 0.832 & 214 & $214(7), 198(100), 182(8)$ \\
\hline 25 & Chlorpyriphos-methyl & 0.843 & 321 & $321(5), 286(100), 125(32)$ \\
\hline 26 & Parathion-methyl & 0.843 & 263 & $263(100), 233(27), 125(65)$ \\
\hline 27 & Simetryn & 0.847 & 213 & $213(100), 198(19), 185(14)$ \\
\hline 28 & Alachlor & 0.854 & 269 & $269(14), 237(26), 160(64)$ \\
\hline 29 & Ametryn & 0.854 & 227 & $227(100), 212(61), 185(22)$ \\
\hline 30 & Prometryn & 0.862 & 241 & $241(100), 226(61), 199(21)$ \\
\hline 31 & Metalaxyl & 0.863 & 279 & $279(20), 249(55), 206(100)$ \\
\hline 32 & Terbutryn & 0.915 & 241 & $241(69), 226(100), 185(66)$ \\
\hline 33 & Pirimiphos-methyl & 0.926 & 305 & $305(84), 290(100), 276(83)$ \\
\hline 34 & Chlorpyriphos-ethyl & 0.959 & 349 & $349(13), 314(100), 286(35)$ \\
\hline 35 & Parathion-ethyl & 0.959 & 291 & $291(100), 261(25), 139(33)$ \\
\hline 36 & Internal standard & 1.000 & 251 & $251(5), 236(9), 222(35)$ \\
\hline 37 & Chlorthion & 1.008 & 297 & $297(100) 267(20), 125(95)$ \\
\hline 38 & Bromophos-methyl & 1.022 & 364 & $364(2), 331(100), 213(8)$ \\
\hline 39 & Butralin & 1.025 & 295 & $295(11), 266(100), 250(12)$ \\
\hline 40 & Isopropalin & 1.042 & 309 & $309(9), 280(100) 264(13)$ \\
\hline 41 & Metazachlor & 1.080 & 277 & $277(23), 209(92), 133(97)$ \\
\hline 42 & Pendimethalin & 1.087 & 281 & $281(13), 252(100), 192(7)$ \\
\hline 43 & Bromophos-ethyl & 1.110 & 392 & $359(100), 303(96), 331(51)$ \\
\hline 44 & Chlorfenvinphos & 1.186 & 358 & $358(3), 267(100), 323(96)$ \\
\hline 45 & Metolachlor & 1.251 & 283 & $283(2), 276(19), 237(37)$ \\
\hline 46 & Jodfenphos & 1.269 & 412 & $412(3), 377(100), 250(7)$ \\
\hline 47 & Prothiophos & 1.281 & 344 & $344(5), 309(100), 267(97)$ \\
\hline 48 & Pretilachlor & 1.336 & 311 & $311(12), 262(27), 238(96)$ \\
\hline 49 & Mepronil & 1.596 & 209 & $209(33), 227(7), 119(100)$ \\
\hline 50 & Azinphos-ethyl & 2.087 & 345 & $345(2), 341(16), 207(52)$ \\
\hline
\end{tabular}

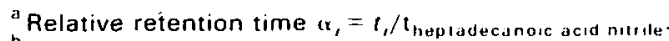

${ }^{b} M_{\mathrm{n}}=$ nominal mass.

cThese columns list the most abundant structurally significant three fragment ions. The abundance in parentheses is listed relatively to the base peak. The quantitation ions are marked in bold letters Internal standard: heptadecanoic acid nitrile.
} 
Table 3. Elution order, detection limits (LOD) in the SCAN and SIM mode, and peak assignment for Figure 3a-d in the SPME-GC/MS analysis of important pesticides

\begin{tabular}{|c|c|c|c|c|}
\hline & Compound & Limit o & (LOD) & \\
\hline No. & Common name & $\begin{array}{l}\mathrm{SCAN}^{\mathrm{a}} \\
\text { (ng/L) }\end{array}$ & $\begin{array}{l}\operatorname{SIM}^{\mathrm{b}} \\
(\mathrm{ng} / \mathrm{L})\end{array}$ & No. ${ }^{\mathrm{C}}$ \\
\hline 1 & Propachlor & 1200 & 32 & $1 \mathrm{a}$ \\
\hline 2 & Ethoprophos & 1100 & 90 & $1 \mathrm{c}$ \\
\hline 3 & Ethalfluralin & 1000 & 11 & $1 \mathrm{~b}$ \\
\hline 4 & Benfluralin & 800 & 7 & $2 b$ \\
\hline 5 & Sulfotep & 270 & 5 & $2 c$ \\
\hline 6 & Atraton & 2400 & 24 & $1 d$ \\
\hline 7 & Simazine & 1200 & 7 & $2 d$ \\
\hline 8 & Prometon & 1200 & 8 & $\cdots$ \\
\hline 9 & Atrazine & 780 & 10 & $3 d$ \\
\hline 10 & Propazine & 750 & 9 & $4 d$ \\
\hline 11 & Terbumeton & 1000 & 13 & - \\
\hline 12 & Terbuthylazine & 2100 & 16 & $5 d$ \\
\hline 13 & Cyanophos & 380 & 36 & $3 c$ \\
\hline 14 & Profluralin & 1200 & 13 & $3 b$ \\
\hline 15 & Diazinon & 1200 & 3 & $4 c$ \\
\hline 16 & Fluchloralin & 1300 & 14 & $4 b$ \\
\hline 17 & Fenfuram & 930 & 5 & $2 a$ \\
\hline 18 & Secbumeton & 1300 & 36 & $6 d$ \\
\hline 19 & Dinitramine & 110 & 4 & $5 b$ \\
\hline 20 & Etrimphos & 1100 & 7 & $5 c$ \\
\hline 21 & Sebuthylazine & 2100 & 34 & $7 d$ \\
\hline 22 & Desmetryn & 1400 & 12 & $8 d$ \\
\hline 23 & Dimethachlor & 830 & 13 & $3 a$ \\
\hline 24 & Metribuzin & 2500 & 110 & $9 d$ \\
\hline 25 & Chlorpyriphos-methyl & 980 & 12 & - \\
\hline 26 & Parathion-methyl & 1000 & 31 & $6 c$ \\
\hline 27 & Simetryn & 1900 & 9 & $10 d$ \\
\hline 28 & Alachlor & 470 & 22 & $4 a$ \\
\hline 29 & Ametryn & 2400 & 9 & $11 d$ \\
\hline 30 & Prometryn & 2300 & 9 & $12 d$ \\
\hline 31 & Metalaxyl & 6000 & 200 & $5 a$ \\
\hline 32 & Terbutryn & 2200 & 15 & $13 d$ \\
\hline 33 & Pirimiphos-methyl & 1800 & 14 & $7 c$ \\
\hline 34 & Chlorpyriphos-ethyl & 970 & 40 & - \\
\hline 35 & Parathion-ethyl & 1000 & 6 & $8 c$ \\
\hline 36 & Internal standard & - & - & - \\
\hline 37 & Chlorthion & 2000 & 34 & $9 c$ \\
\hline 38 & Bromophos-methyl & 3000 & 10 & $10 \mathrm{c}$ \\
\hline 39 & Butralin & 410 & 25 & $6 a, 6 b$ \\
\hline 40 & Isopropalin & 2600 & 20 & $7 b$ \\
\hline 41 & Metazachlor & 1900 & 55 & $7 a$ \\
\hline 42 & Pendimethalin & 810 & 42 & $8 b$ \\
\hline 43 & Bromophos-ethyl & 4300 & 12 & $11 \mathrm{c}$ \\
\hline 44 & Chlorfenvinphos & 5400 & 48 & $12 c$ \\
\hline 45 & Metolachlor & 400 & 13 & $8 a$ \\
\hline 46 & Jodfenphos & 7200 & 16 & $13 c$ \\
\hline 47 & Prothiophos & 6200 & 46 & $14 c$ \\
\hline 48 & Pretilachlor & 880 & 50 & $9 a$ \\
\hline 49 & Mepronil & 1100 & 22 & $10 a$ \\
\hline 50 & Azinphos-ethyl & 3100 & 36 & $15 c$ \\
\hline
\end{tabular}

${ }^{a}$ Signal-to-noise ratio $=3$

${ }^{b}$ Signal-to-noise ratio $=3$, for quantitation ion, see Table 2

c Number of peak in Figure $3 a-d$.

Internal standard: heptadecanoic acid nitrile. 


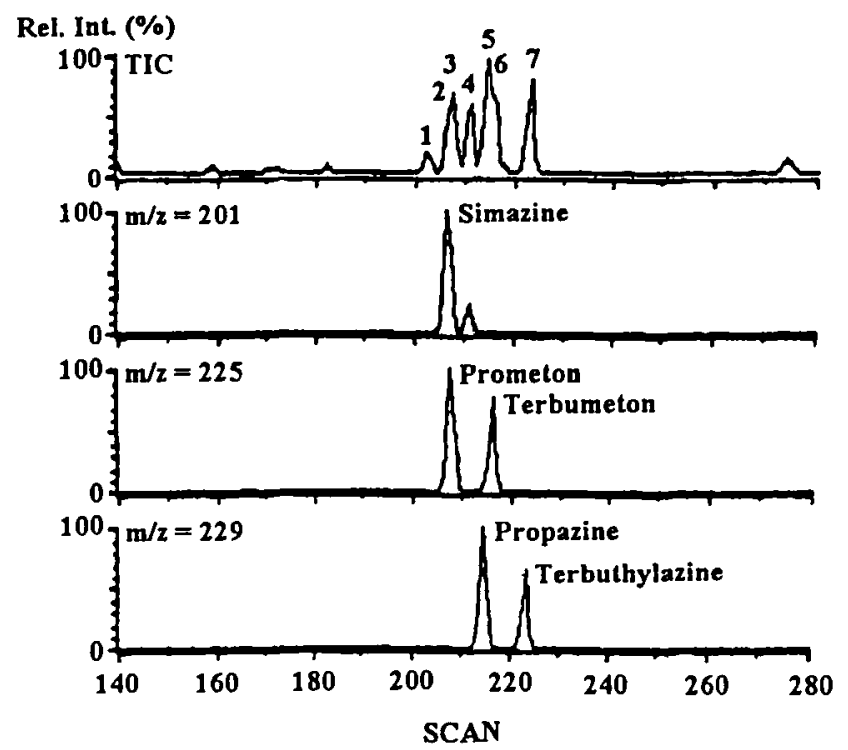

Figure 5. Separation of the coclution peaks of simazine-prometon and propazine-terbumeton by using their characteristic ions (simazine, 201; prometon, 225; propazine, 229; terbumeton, 225).

most pesticides, a precise quantification is possible if this extraction time is kept exactly constant (tolerance of only a few seconds). Further improvement of the precision should be achievable by using an automated SPME injection system. Figure 5 shows the separation of the coelution peaks simazine-prometon and propazine-terbumeton by monitoring their characteristic ions, which enhances the precision.

\section{Further Parameters that Influence the Solid-Phase Microextraction of Pesticides}

Salt effect. The addition of a salt (sodium chloride in most instances) often improves the recovery when conventional extraction methods are used. Also, in the case of SPME, the addition of sodium chloride to the aqueous sample improves the extraction as studied for the triazine and anilide pesticides. This effect is particularly pronounced for very polar, that is, hydrophilic compounds. Organophosphorus pesticides show a different behavior when sodium chloride is added. The response of most of these compounds decreases with high sodium chloride concentrations. Thus, the effect of salt addition is more pronounced in relation to lower hydrophobicity, that is, the addition of salt improves, in particular, the extraction of those compounds that, as a result of low hydrophobicity, are difficult to extract. For the investigated triazines, the addition of sodium chloride (saturated solution) leads to an almost equal peak response for all compounds comparable to that of the standard chromatogram prior to SPME extraction. Finally, it should be noted that the addition of sodium chloride will further reduce the limit of detection and extend the linear range.

Addition of humic acids. In this experiment, the concentration of humic acids was varied between 0.1 and
$100 \mathrm{mg} / \mathrm{L}$, which are typical DOC (dissolved organic carbon) values determined in surface water samples [34]. Figure 6a demonstrates that for triazines, humic acids have little effect on the extraction efficiency. Only at the DOC of humic acid concentration of $100 \mathrm{mg} / \mathrm{L}$ did the response monitored for simetryn and terbutryn decrease $>20 \%$ (see Figure $6 a$ ).

Competition of major and minor components during the SPME process. It is conceivable that a high content of organics (e.g., solvents) precludes an efficient extraction. To study this effect, different amounts of terbuthylazine, a compound with a high affinity to the polymeric fiber, were added in concentrations that ranged from 18 to $12,000 \mathrm{ng} / \mathrm{mL}$. Although the concentration is varied over 3 orders of magnitude, no significant
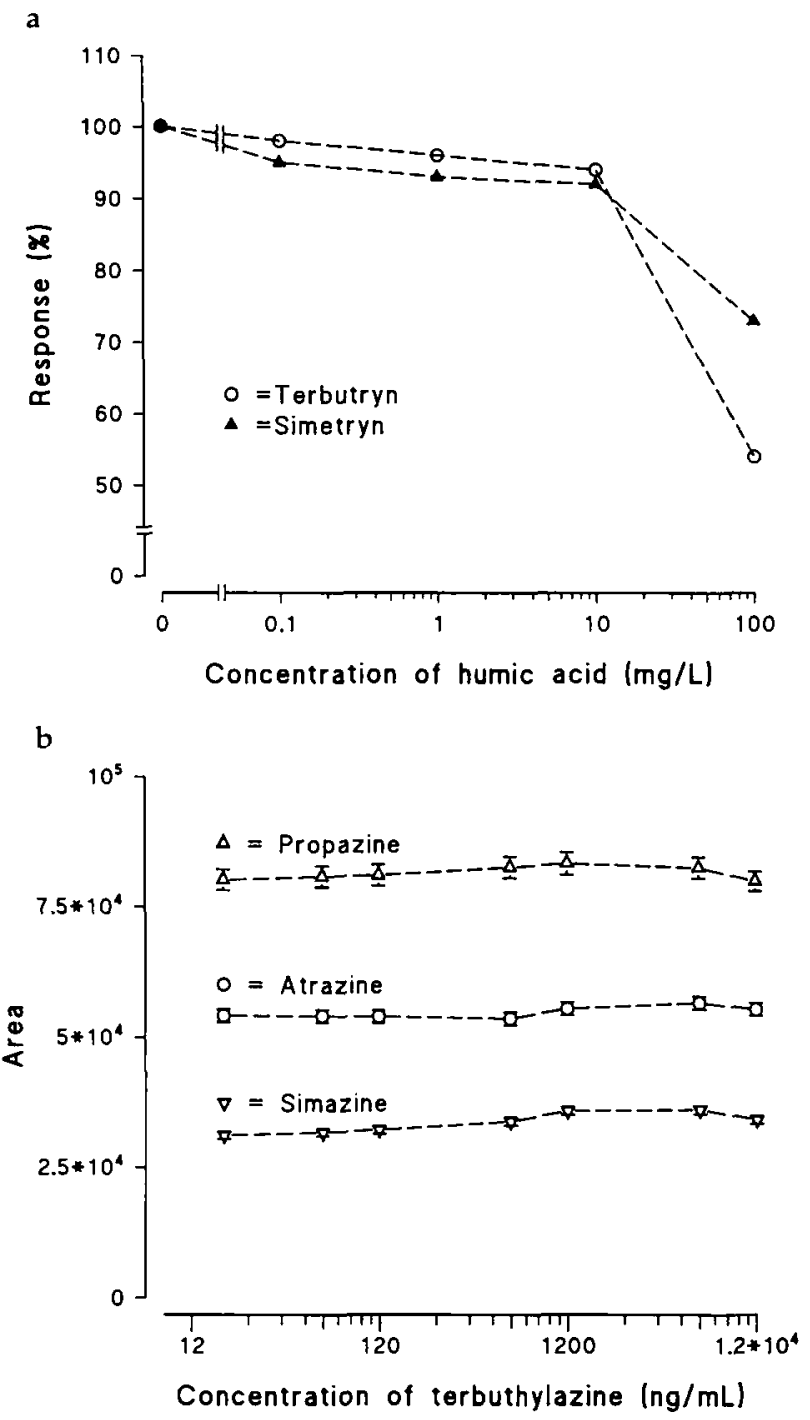

Figure 6. (a) Dependence of the peak response (extraction efficiency in percent) on the addition of humic acids that range from 0.1 to $100 \mathrm{mg} / \mathrm{L}$, demonstrated for simetryn and terbutryn. (b) Dependence of the peak response (extraction efficiency in percent) on terbuthylazine content for three other triazine pesticides. The concentration of terbuthylazine addition ranges from 18 to $12,000 \mathrm{ng} / \mathrm{mL}$. 
decrease in peak response for all the other investigated pesticides (which had been kept at a constant concentration level of $18 \mathrm{ng} / \mathrm{mL}$ ) was observed (see Figure $6 \mathrm{~b})$. Thus, the effect of excess concentration of organics with high affinities to the SPME fiber on the extraction efficiency of other analytes in the low parts per trillion to low parts per billion range is less pronounced than expected.

Furthermore, the influence of methanol on peak responses was studied in several experiments by varying the amount of methanol from a few up to several percent (vol) during the SPME extraction. An increase in the methanol content up to $20 \mathrm{vol} \%$ reduced the peak response for the investigated triazine compounds by a factor of -2 . Reasonable extractions may still be carried out at a methanol concentration of $<10 \mathrm{vol} \%$.

\section{Environmental Samples}

It is conceivable that solid-phase microextraction is less effective if environmental samples are analyzed because in this case many often unknown matrix components compete with the analytes for absorption by the polymer. Figure 7 shows the GC/MS chromatogram of a water sample from the effluent of a

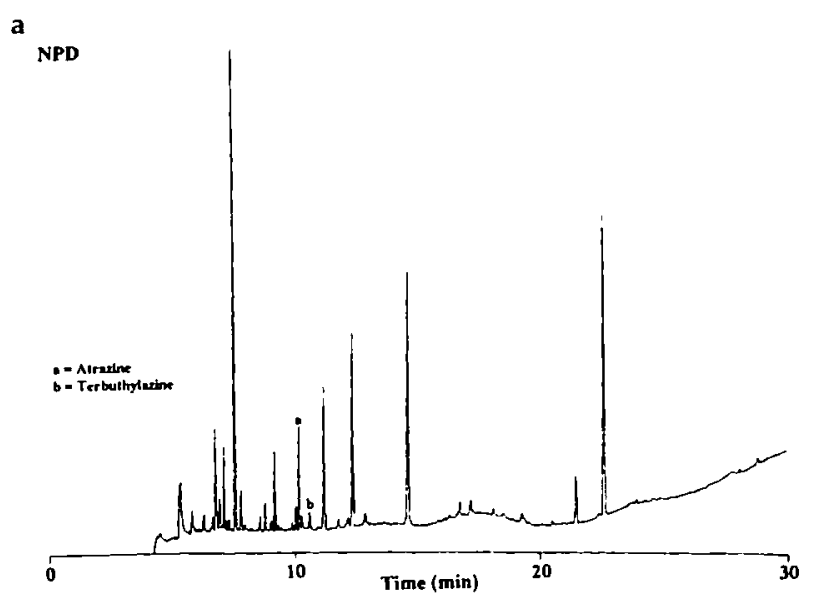

b

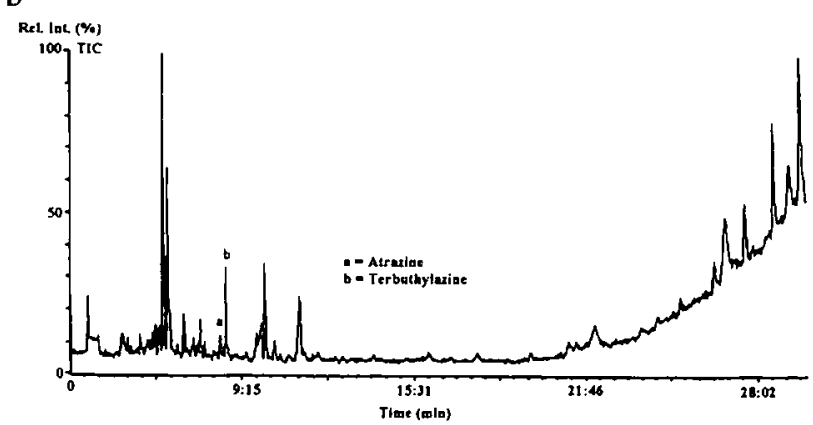

Figure 7. Gas chromatogram of a wastewater sample from a sewage plant extracted by SPME $(85-\mu \mathrm{m}$ polyacrylate fiber) obtained by nitrogen-phosphorous (a) and mass selective (b) detection: $a=$ atrazine; $b=$ terbuthylazine. The concentrations of these two identified triazines are atrazine, $1010 \mathrm{ng} / \mathrm{L}$ and terbuthylazine, $70 \mathrm{ng} / \mathrm{L}$. sewage plant (near Darmstadt, Germany) that was extracted by SPME under standard conditions via a sodium chloride-saturated sample. Three s-triazines (atrazine, simazine, and terbuthylazine) were first tentatively identified by GC/NPD and later confirmed by GC/MS. In the latter case, all pesticides were identified by three characteristic ions (see Table 2). A typical result of a mass spectrometry identification of atrazine and terbuthylazine in a waste effluent sample is shown in Figure $8 \mathrm{a}$ and $\mathrm{b}$. Verification was achieved by monitoring the ions $215[\mathrm{M}]^{+}, 217$ (chlorine isotope peak), and $200\left[\mathrm{M}-\mathrm{CH}_{3}\right]^{+}$for atrazine and $229[\mathrm{M}]^{+}, 231$ (chlorine isotope peak), and $214\left[\mathrm{M}-\mathrm{CH}_{3}\right]^{+}$for terbuthylazine (see Figures 8 and 9). For these two pesticides, concentrations that ranged from 70 to $1010 \mathrm{ng} / \mathrm{L}$ were determined. One can conclude from this comparison that even in heavily contaminated environmental samples, SPME coupled to GC/MS allows the determination of these pesticides at very low concentration

a

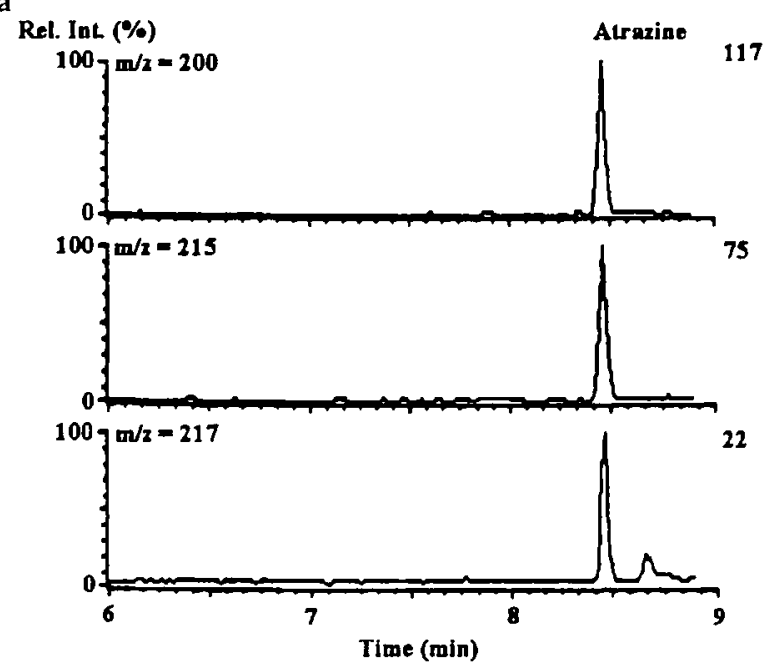

b

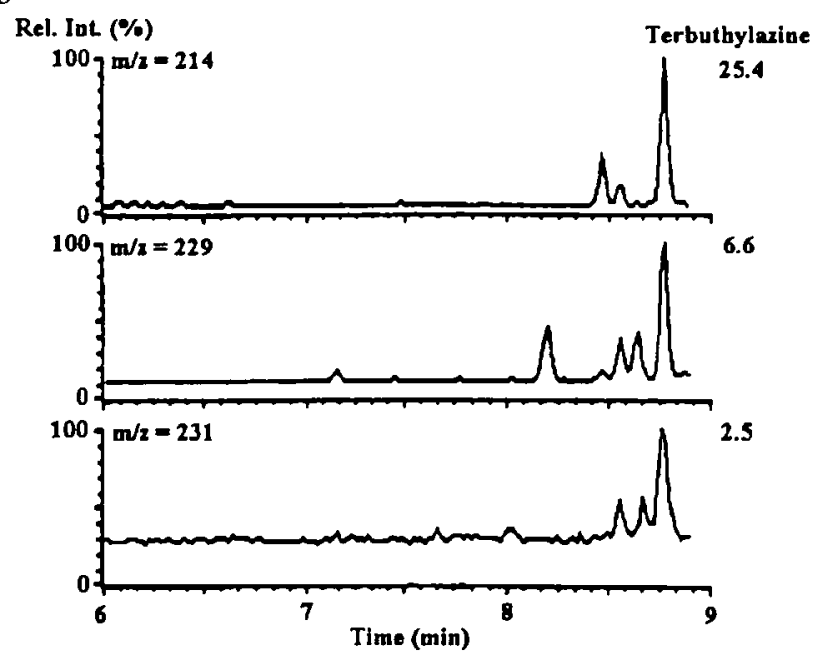

Figure 8. Identification of atrazine (a) and terbuthylazine (b) in a wastepipe sample via SPME. The sample was saturated by $\mathrm{NaCl}$. In both cases all three typical ions can be observed at a certain retention time. 


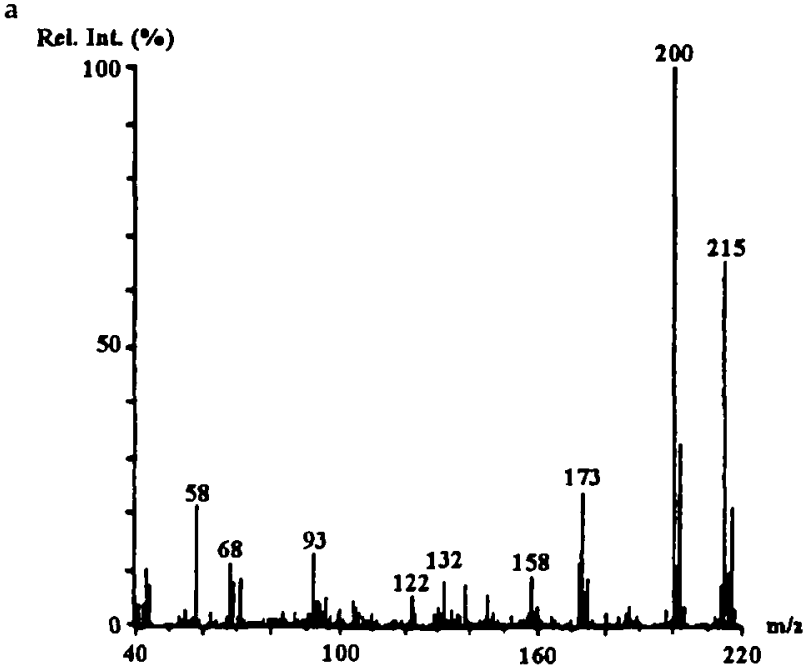

b

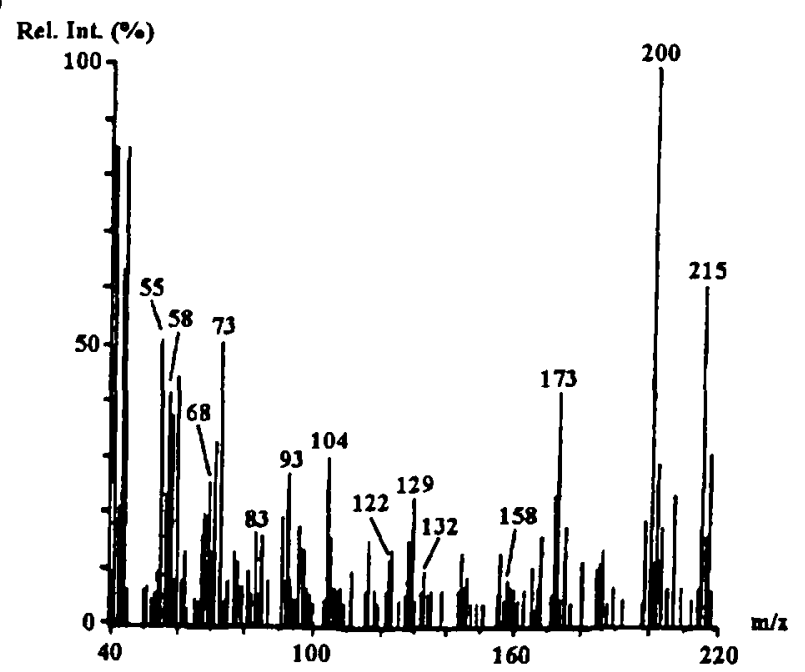

Figure 9. Mass spectra obtained for atrazine from a SPME of a standard (a) and from the wastepipe sample (b) shown in Figure 7.

levels down to $100 \mathrm{ng} / \mathrm{L}$. The concentrations determined with SPME-GC/MS were in close agreement with those determined with conventional SPE-GC/MS. Residues of triazines, particularly atrazine and its metabolites, are frequently detected in aqueous environmental samples owing to their persistance and relatively high solubility in water as reported by many authors [35-37].

\section{Conclusions}

In this study, solid-phase microextraction has been applied to the determination of pesticides (triazine, organophosphorus, and anilide compounds). These compounds are three important pesticide classes that have relatively high polarity. The extraction efficiency strongly depends on the polarity (or hydrophobicity) of the individual compound, that is, the less polar or the more hydrophobic the compounds, the higher their affinity to the polyacrylate phase and the more efficient their extraction. This effect can, however, be overcome by the addition of sodium chloride, which increases the ionic strength of the aqueous phase. This leads to a general increase in extraction efficiency for all compounds, where the largest effect is observed for the polar compounds (with low octanol-water partitioning coefficient, $P_{\text {ow }}$ ). Hence, this salt effect leads, for example, to almost equal extraction efficiencies for triazine pesticides. The results for the anilines are very similar to those of the triazines, whereas for the organophosphorus pesticides there is a strong decrease in affinities to the fiber after addition of $\mathrm{NaCl}$ to the aqueous sample.

Successful in-line SPME-GC/MS of 49 pesticides from aqueous samples has been demonstrated. The major advantages of this technique are (1) the extraction is achieved without the use of solvents, (2) the method is very simple and fast, (3) the method is very sensitive when coupled in-line to gas chromatograph and very selective when coupled to a gas chromatography mass spectrometer, and (4) the method is rugged. Thus, high humic acid and other organics contents do not interfere with the extraction. Other advantages of this technique are that (5) only a very small sample volume $(-3-5 \mathrm{~mL})$ is necessary for the SPME, (6) coeluting compounds can be easily separated by their characteristic masses, and (7) the fiber can be used repeatedly (in contrast to the normal solid-phase extraction (SPE) where the cartridge is discarded after use]. No significant memory effect is observed under desorption conditions for SPME injection as detailed in the foregoing text. The small sample volume necessary may be attractive for many applications where the sample volume is limited, for example, cloud, rain, or sediment water.

SPME can be readily coupled to a gas chromatograph (in-line coupling). However, if organic pollutants in the parts per trillion range are to be determined, GC/MS is more selective. SPME combined with a gas chromatograph with mass selective detection enables very low limits of detection $(<50 \mathrm{ng} / \mathrm{L}$ in the SIM mode) to be achieved, because the total amount of analytes extracted is used for determination. Thus, the maximum level set by the European Union for pesticides and drinking water can be verified without difficulty.

\section{Acknowledgments}

Financial support from the Commission of the European Communities EC Avicenne programme (Contract AVI*-CT92-0004) is kindly acknowledged. The authors wish to thank Dr. T. Knepper from the ESWE "Institut für Wasserforschung und Wassertechnologie" (Wiesbaden, Germany), who provided the wastewater samples from sewage plants.

\section{References}

1. Junk, G. A.; Richard, J. J. Anal. Chem. 1988, 60, 451-454.

2. Loconto, P. R.; Gaind, A. K. J. Chromatogr. Sci. 1989, 27, 569-573. 
3. Eisert, R.; Levsen, K.; Wünsch, G. Int. I. Environ. Anal Chem. 1995, 58, 103-120.

4. Bolygó, E.; Atreya, N. C. Freseninis J. Anal. Chem. 1991, 339, 423-430.

5. Lartiges, S.; Garrigues, P. Analusis 1993, 21, 157-165.

6. Belardi, R. P.; Pawliszyn, J. Water Pollution Res. J. Canada 1989, 24, 179-191.

7. Arthur, C. L.; Pawliszyn, J. Anal. Chem. 1990, 62, 2145-2148.

8. Arthur, C. L.; Killam, L. M.; Buchholz, K. D.; Pawliszyn, J.; Berg, J. R. Anal. Chem. 1992, 64, 1960-1966.

9. Louch, D.; Motlagh, S.; Pawliszyn, J. Anal. Chem. 1992, 64, $1187-1199$

10. Arthur, C. L.; Killam, L. M.; Motlagh, S.; Lim, M.; Potter, D. W.; Pawliszyn, J. Environ. Sci. Technol. 1992, 26, 979-983.

11. Chai, M.; Arthur, C. L.; Pawliszyn, J.; Belardi, R. P.; Pratt, K. F. Analyst 1993, 188, 1501-1505.

12. Zhang, Z.; Pawliszyn, J. I. High. Resolution Chromatogr. 1993, $16,689-692$.

13. Potter, D. W.; Pawliszyn, J. Environ. Sci. Technol. 1994, 28, 298-305.

14. Buchholz, K. D.; Pawliszyn, J. Environ. Sci. Technol. 1993, 27, 2844-2848.

15. Buchholz, K. D.; Pawliszyn, J. Anal. Chem. 1994, 66, 160-167.

16. Zhang, Z.; Pawliszyn, J. Anal. Clem. 1995, 67, 34-43.

17. Berg, J. R. Am. Lab. 1993, 25, 18-24.

18. Zhang, Z.; Pawliszyn, J. Anal. Chem. 1993, 65, 1843-1852.

19. Arthur, C. L.; Potter, D. W.; Buchholz, K. D.; Motlagh, S.; Pawliszyn, J. LC-CC 1992, 10,656-661.

20. Arthur, C. L.; Chai, M.; Pawliszyn, J. I. Microcol. Sep. 1993, 5, 51-56.

21. Hawthorne, S. B.; Miller, D. J.; Pawliszyn, J.; Arthur, C. L. J. Chromatogr. 1992, 603, 185-191.
22. Potter, D. W.; Pawliszyn, J. 1. Chromatogr. 1992, 625, 247-255.

23. Page, B. D.; Lacroix, G. I. Chromatogr. 1993, 648, 199-211.

24. Arthur, C. L.; Pratt, K.; Motlagh, S.; Pawliszyn, J.; Belardi, R. P. J. High Resolution Chromatogr. 1992, 15, 741-744.

25. Motlagh, S.; Pawliszyn, J. Anal. Chim. Acta 1993, 284, 265-273.

26. Chiarotti, M.; Marsilli, R. 1. Microcol. Scp. 1994, 6, 577-580.

27. Popp, P.; Kalbitz, K.; Oppermann, G. J. Clromatogr. A 1994, $687,133-140$

28. Zhang, Z.; Yang, M. J.; Pawliszyn, J. Anal. Chem. 1994, 66, $844 \mathrm{~A}-853 \mathrm{~A}$.

29. U.S. Environmental Protection Agency, National Survey of Pesticides in Drinking Water Wells, Phase I Report; EPA570/9-90-015; Office of Water and Office of Pesticides Programs, U.S. Government Printing Office: Washington, DC, 1990.

30. Commission of the European Communities, EEC Drinking Water Guideline; 80/779/EEC, EEC No. L229/11-29; EEC: Brussels, 1980.

31. Eisert, R.; Levsen, K.; Wünsch, G. /. Chromatogr. A 1994, 683. 175-183.

32. Eisert, R.; Levsen, K. Fres'nius I. Anal. Ch'm. 1995, 351, $555-562$.

33. Noble, A. J. Cliromatogr. 1993, 642, 3-14.

34. Huber, S. A.; Balz, A.; Frimmel, F. H. Fresenius ]. Altal. Clom. 1994, 350, 496-503.

35. Cai, Z.; Sadagopa Ramanujam, V. M.; Giblin, D. E.; Gross, M. L.; Spalding, R. F. Anal. Chem. 1993, 65, 21-26.

36. Caldwell, K. A.; Sadagopa Ramanujam, V. M.; Cai, Z.; Gross, M. L.; Spalding, R. F. Alnal. Clem. 1993, 65, 2372-2379.

37. Cai, Z.; Sadagopa Ramanujam, V. M.; Gross, M. L; Monson, S. I.; Cassada, D. A.; Spalding, R. F. Anal. Chom. 1994, 66, $4202-4209$. 